\title{
The puzzle of vertigo and migraine
}

The association between migraine and various vertigo syndromes is well recognised. Migraine headaches are common, and frequently co-exist with benign paroxysmal positional vertigo, Ménière's disease and less well-defined vertiginous disorders. In this issue of The Journal of Laryngology \& Otology, a study by Foster and Pollard seeks to investigate potential differences in vestibular function between those with and without migraine. ${ }^{1}$ They found that although caloric responses were not significantly different, migraine sufferers experienced vestibular stimuli more intensely than non-sufferers, which might explain the link between migraine and vestibular disorders. A previous article also examined vestibular function in migraine patients. Baker and colleagues found that there were differences in the vestibular ocular reflexes between migraine sufferers and a normal population, suggesting that vestibular rehabilitation for migrainous vertigo should focus on vestibular ocular reflexes and functional retraining. ${ }^{2}$

Staying with vertigo, there is a lack of consensus as to the optimum dosage and method of administration of intratympanic gentamicin therapy for Ménière's disease. Watson and colleagues present their experience, and advocate a low-dose regime as being effective, while potentially causing less cochlear toxicity and hearing loss. ${ }^{3}$ Other authors have suggested a much more intense high-dose regime as effective in producing both short- and long-term improvements in Ménière's disease patients. ${ }^{4}$

Finally, in this issue, we once again feature the everpresent risk of litigation in modern medical practice. ${ }^{5,6}$
As Metcalfe and colleagues point out in their review, litigation in surgery is increasing and liabilities are becoming unsustainable. ${ }^{5}$ In the National Health Service in England, claims within ENT are relatively infrequent, but potentially very costly. Over half of claims relate to the five most common areas of litigation (i.e. failure or delay in diagnosis, intra-operative problems, failure or delay in treatment, and inappropriate treatment). Increasing claims are occurring despite initiatives such as the World Health Organization's 'Safe Surgery Saves Lives'.

\section{ROBIN YOUNGS EDWARD FISHER Senior Editors}

\section{References}

1 Foster CA, Pollard CK. Comparison of caloric reactivity between migraineurs and non-migraineurs. J Laryngol Otol 2015;129: 960-63

2 Baker BJ, Curtis A, Trueblood P, Vangsnes E. Vestibular functioning and migraine: comparing those with and without vertigo to a normal population. J Laryngol Otol 2013;127:1169-76

3 Watson GJ, Nelson C, Irving RM. Is low-dose intratympanic gentamicin an effective treatment for Ménière's disease: the Birmingham experience. J Laryngol Otol 2015;129:970-73

4 Wasson J, Upile N, Pfleiderer A. Intratympanic gentamicin treatment for unilateral Ménière's disease: long-term follow up of a proven regime. J Laryngol Otol 2013;127:20-4

5 Metcalfe CW, Muzaffar SJ, Coulson CJ. Litigation trends and costs in otorhinolaryngology. J Laryngol Otol 2015;129: 941-44

6 Veer V, Jackson L, Kara N, Hawthorne M. Pre-operative considerations in aesthetic facial surgery. J Laryngol Otol 2015;128: $22-8$ 